\title{
Burnout and Health Promotion among Physicians from Across the Globe
}

Brenda L. Lovell ${ }^{1}$, Laura Schwartzmann ${ }^{2}$, Raymond T. Lee ${ }^{3}$

Independent consultant, 1 Glengarry Dr., Winnipeg, MB, R3T 2J5, Canada

2 Associate professor, Facultad de Medicina, Universidad de la República Oriental del Uruguay, Montevideo, Uruguay

3 Human resource management consultant and professor, University of Manitoba, Winnipeg, Canada

We recently completed a meta-analysis study on physician burnout from around the world. It found that physicians from North America, South America, and Europe to be at high risk for the burnout dimension of Emotional Exhaustion (EE) [1]. Among the most important organizational/workplace factors identified in our study as major burnout risks are excessive workload, which is closely connected to work-life conflict. Both factors were closely associated with high levels of EE, especially for physicians from the Americas. At the individual level, emotional distress and ineffective coping strategies, such as overeating, alcohol and drug consumption, were strong contributors to poor health, which we also found to be closely associated with high levels of EE. Our overall findings reveal that individual and social factors, rather than just workplace factors, were tied to mental health outcomes.

The burnout risk factors we identified underscore the need to develop mental health promotion programs to improve work satisfaction, mental wellness, and quality of patient care.

\section{What is mental health promotion?}

Broadly speaking, it involves actions that support people to adopt and maintain healthy lifestyles, and which create supportive living conditions or environments for health [2]. Mental health promotion efforts will be more effectively implemented with active participation from all health professionals, organization/workplace, and community. What role can the community play? For example, at the community level, a study sponsored by the Patients' Care and Safety Committee of the Ministry of Health in Uruguay is currently underway to address disruptive workplace behavior and inform preventative interventions. Human resource planning should include more than implementing salary increases. A case study from Ghana showed that while providing greater salaries may have stemmed migration, it did not lead to increased productivity in health workers [3]. Thus, workplaces and educational institu- 
tions play a vital role in promoting mental wellness through the training of physicians and other health professionals on managing life, emotions, thoughts and feelings [2].

Our research did not include sufficient samples of physicians from Asia, Middle East and Africa either because of a lack of studies in these regions, or the studies were published in languages other than English or Spanish. More research needs to be conducted in these regions to determine where similarities and/or differences exist on the burnout correlates. This would help to identify common characteristics and risk factors for poor mental health, as well as suggest possible cultural variations that may impact health promotion efforts [2].

\section{Conclusions}

In the near future, we will extend our meta-analysis study of physicians by identifying the correlates linked to the personal accomplishment dimension of burnout. This follow-up research will shed light on the specific individual, workplace and community level factors that contribute to increased mental wellness, which itself would be closely linked to career satisfaction and quality of care.

\section{References}

1. Lee RT, Seo B, Hladkyj S, et al. Correlates of physician burnout across regions and specialties: a meta-analysis. Hum Resour Healt 2013; 11: 48; http://dx.doi.org/10.1186/1478-4491-11-48

2. Promoting Mental Health: Concepts, Emerging Evidence, Practice. World Health Organization, 2004.Available at: http://www.who.int/mental_health/evidence/en/promoting_mhh.pdf

3. Ghana: Implementing a national human resources for health plan. World Health Organization, 2008. Available at: http://www.who.int/workforcealliance/knowledge/case_studies/CS_Ghana_ web_en.pdf 